\title{
COVID-19 Among Doctors in Indonesia: Risk of Moderate-Severe and Behavior Adaptation in Personal Protective Equipments Usage After Infection
}

\section{Evy Yunihastuti ( $\square$ evy.yunihastuti@gmail.com )}

Department of Internal Medicine, Cipto Mangunkusumo Hospital - Faculty of Medicine, Universitas Indonesia, Jakarta

\section{Ari Fahrial Syam}

Department of Internal Medicine, Cipto Mangunkusumo Hospital - Faculty of Medicine, Universitas Indonesia, Jakarta

Herikurniawan Herikurniawan

Department of Internal Medicine, Cipto Mangunkusumo Hospital - Faculty of Medicine, Universitas Indonesia, Jakarta

\section{Dewi Sumaryani Soemarko}

Department of Community Medicine, Faculty of Medicine, Universitas Indonesia, Jakarta

\section{Andrian Wiraguna}

Faculty of Medicine, Universitas Indonesia, Jakarta

\section{Research Article}

Keywords: COVID-19, Personal protective equipment (PPE)

Posted Date: October 7th, 2021

DOl: https://doi.org/10.21203/rs.3.rs-944448/v1

License: (1) (i) This work is licensed under a Creative Commons Attribution 4.0 International License. Read Full License 


\section{Abstract}

Doctors have a greater risk of acquiring COVID-19 due to occupational exposure. Personal protective equipment (PPE) is an essential factor in reducing COVID-19 transmission. We aimed to evaluate the risk of moderate-severe COVID-19 infection and behavior adaptation in PPE usage among doctors who survived COVID-19 in Indonesia. This was an online population-based cross-sectional survey among Indonesian doctors of COVID-19 survivors. Bivariate and multivariate analyses were performed to determine factors associated with moderate-severe COVID-19 infection. A total of 389 doctors who survived COVID-19 infection across in Indonesia was included in this study. Most participants were young doctors (20-39 years: 69.7\%), general practitioners (50.4\%), working in COVID-19 designated hospitals (62.5\%), and worked more than 40 hours/week (57.8\%). Factors associated with moderate-severe COVID19 were IMA moderate occupational risk (aOR 4.14, 95\% Cl: 1.11-15.47), age 40-59 years (aOR 3.24, 95\% Cl: 1.99-5.29), working in COVID-19 designated hospital (aOR 1.89, 95\% Cl: 1.18-3.01), and higher BMI (aOR 1.88, 95\% Cl: 1.00-3.54). N95 respirator and other PPEs use improved after these doctors recovered from COVID-19 infection in isolation and non-isolation rooms. In conclusion, working COVID-19 designated hospital, moderate occupational risk, higher BMI, and age 40-59 were associated with moderate-severe COVID-19 among doctors in Indonesia.

\section{Introduction}

Coronavirus disease 2019 (COVID-19) has become a global public health threat and evolved into a worldwide pandemic crisis ${ }^{1}$. World Health Organization (WHO) declared COVID-19 as public health emergency on 2020 January 30 and called of all countries to prevent the rapid spread of COVID-192. Indonesia is a country that was hit hard by this pandemic. Confirmed cases from the beginning of the pandemic until June 2021 reached 1.531.005 with 83.700 (5.5\%) active cases, 1.404 .639 (91.7\%) recovered cases and $42.666(2.8 \%)$ mortality cases ${ }^{3}$. The Government has implemented public health protocols to control the spread of the virus, such as physical and social distancing, hand washing, and mask use, but the active cases are still increasing ${ }^{4}$. The public healthcare systems are not prepared to face this devastating situation.

Healthcare workers (HCWs) have a higher risk of acquiring COVID-19 due to increased occupational exposure to SARS-CoV-2 ${ }^{5,6}$. Within three months (March-May 2020), the Centers for Disease Control and Prevention (CDC) reported that $5.9 \%$ of the hospitalized patients in United States were health workers ${ }^{7}$. The lack of accurate information regarding disease management, limited availability of adequate personal protective equipment (PPE), limited diagnostic test kits, psychosocial factors such as an unsupportive work environment, and excessive workload increased the number of HCWs-infected COVID19 , especially in the early of the pandemic ${ }^{8-10}$. There was no official report for the number of HCWsinfected with COVID-19 in Indonesia. The first case of an Indonesian doctor died of COVID-19 was published on March 22, 2020. In June 2021, the Indonesian Medical Association (IMA) reported that there were 374 doctor deaths due to COVID-1911. 
Several factors that known to increase the severity of COVID-19 infection are age, pre-existing comorbidities and complications, obesity, and smoking status ${ }^{12-15}$. Health care workers might have additional risk factors that increase the severity of COVID-19 infection, ie excessive workload and reuse of disposable PPE ${ }^{16,17}$. We tried to evaluate the risk of moderate-severe among doctors in Indonesia who survived from COVID-19. In addition, behavioral adaptation in PPE usage among this population before and after being infected with COVID-19 were assessed.

\section{Methods}

Participants and procedure. This was an online population-based cross-sectional study. The survey was conducted from October-December 2020 among Indonesian doctors of COVID-19 survivors. The questionnaire was designed for Google survey tool (Google Forms) and the generated link was shared to public on social media and also shared personally to the contact list of investigators. The inclusion criteria of this survey were Indonesian doctors who registered in the Indonesian Medical Association, run a medical practice, and have a history of confirmed COVID-19 infection. The diagnosis of COVID-19 was confirmed by real-time polymerase chain reaction (RT-PCR) for SARS-CoV-2 done on nasopharyngealoropharyngeal swab specimens. Participants who do not fill out incomplete survey data were excluded from the analysis.

Measures. Socio-demographic information collected were age, gender, marital status, profession, working in COVID-19 designated hospital, working hours per week, occupational risk stratification, body mass index (BMI), smoking status, suspected sources and location of transmission. Occupational risk stratification based on Indonesian Medical Association was categorized into four groups: low risk (do not have contact with suspect/probable/confirmed COVID-19), moderate risk (have contact with many people who unknown their COVID-19 status), high risk (have close contact with suspect/probable/confirmed COVID-19), and very high risk (have close contact and doing aerosol medical procedures in COVID-19 patients $)^{18}$. Description of COVID-19 infection history included date of first PCR-SARS-CoV-2 confirmed, clinical symptoms, comorbidities, disease severity, hospitalization, and long-haulers COVID-19 symptoms.

We evaluated the use of several PPEs before and after COVID-19 infection in several working locations. Special isolation ward with aerosol generating procedure was considered as isolation room, while emergency department, non-isolation ward, critical care unit, operating room, other procedural room, and outpatient unit were considered as non-isolation room. We asked the participants about the use standardized filtering face-piece respirator N95 and other type of mask, including non-standardized KN95, surgical mask, and fabric mask. N95 was considered an adequate standard for the COVID-19 pandemic. For those who used N95, we further evaluated the reusing practice of N95 respirator. Other personal protective equipment interests were surgical cap, eye protection (goggles), face protection, coverall, long sleeve gowns, and gloves. The use of shoe covers (boots) and coverall was asked only for those working in isolation room. Each PPE item use had a possible response of "never", "sometimes", and "always". These possible responses were also applied in the reusing practice of N95 respirator. 
Statistical analysis. The data analysis was performed using SPSS version 25.0 (IBM® SPSS ${ }^{\circledR}$ Statistics 25). Bivariate and multivariate analyses were performed using chi-square test and binary logistic regression to determine factors associated with moderate-severe COVID-19 infection.

Ethical considerations. This study was approved by the Health Research Ethics Committee, Faculty of Medicine, Universitas Indonesia-Cipto Mangunkusumo Hospital (KET-

1114/UN2.F1/ETIK/PPM.00.02/2020). All participants who agreed to participate in this study provided online informed consent form on the first page of the survey before continue responding to the online self-report survey. All procedures in this study were conducted in accordance with the Declaration of Helsinki, as revised in 2013.

\section{Results}

Socio-demographics characteristic. A total of 389 doctors who survived COVID-19 infection were included in the final analyses. These participants were spread across 25 of 34 provinces in Indonesia. The highest number of participants were Jakarta, West Java, and Banten $(46.1 \%, 11.0 \%$, and $6.4 \%$ of total participants, respectively) as seen in Figure 1.

Most of the participants were young doctors (20-39 years: 69.7\%), general practitioners (50.4\%), working in COVID-19 designated hospitals (62.5\%), and had worked more than 40 hours per week (57.8\%). Almost half of suspected transmission source was from the patients $(47.8 \%)$, followed by their medical colleagues (15.4\%), and other health care workers (7.5\%). Eighty percents HCWs thought that they got infection in their workplaces (80.5\%). Fifty five percents of participants were not hospitalized during infection as seen in Table 1. 
Table 1

Characteristics of study participants $(n=389)$.

n (\%)

A. SOCIO-DEMOGRAPHIC

Age

20-39 years

$271(69.7)$

40-59 ears

$106(27.2)$

$\geq 60$ years

$12(3.1)$

Male gender

$167(43.0)$

Married

$291(74.8)$

Profession

General practitioner

$196(50.4)$

Specialist - consultant

$120(30.8)$

Resident

$73(18.8)$

Working in COVID-19 designated hospital

$243(62.5)$

Working $>40$ hours per week

$225(57.8)$

IMA occupational risk stratification

Low

$19(4.9)$

Moderate

163 (41.9)

High

$160(41.1)$

Very high

$47(12.1)$

Body mass index

$<18.5$ (underweight)

$4(1.0)$

18.5-22.9 (normal)

77 (19.8)

23.0-24.9 (overweight)

$81(20.8)$

$>25.0$ (obesity)

227 (58.4)

$\geq 1$ high risk comorbidities*

$102(26.2)$

Smoker

$7(1.8)$

*) Hypertension, type 2 diabetes mellitus, heart disease, chronic pulmonary obstructive disease, asthma, autoimmune disease, hematological disease, and cancer. **) Nurse, midwifes, nutritionist, etc. ${ }^{* * *)}$ Drivers, housemaid, security, etc. 
n (\%)

B. CLINICAL DATA

Clinical symptoms

Fever or history of fever $189(60.8)$

Myalgia

$182(58.5)$

Cough

$171(55.0)$

Malaise

$162(52.1)$

Anosmia

155 (49.8)

Dysgeusia

142 (45.7)

Headache

131 (42.1)

Sore throat

$122(39.2)$

Diarrhea

118 (37.9)

Common cold

111 (35.7)

Nausea - vomitus

108 (34.7)

Shortness of breath

$82(26.4)$

Anorexia

65 (20.9)

Insomnia

$53(17.0)$

Abdominal pain

$42(13.5)$

Skin abnormality

$26(8.4)$

Conjuctivitis

$17(5.5)$

Suspected location of transmission

Workplaces

$313(80.5)$

Home

$33(8.5)$

Public places

$28(7.2)$

Unknown

$15(3.8)$

*) Hypertension, type 2 diabetes mellitus, heart disease, chronic pulmonary obstructive disease, asthma, autoimmune disease, hematological disease, and cancer. **) Nurse, midwifes, nutritionist, etc. **) Drivers, housemaid, security, etc. 
n (\%)

Suspected sources of transmission

Patients $186(47.8)$

Colleagues

60 (15.4)

Family $42(10.8)$

Unknown

41 (10.5)

Other health workers **

Others***

$21(5.4)$

Other friends

$7(1.8)$

Administrative staff

$3(0.8)$

Severity COVID-19

Asymptomatic

$96(24.7)$

Mild

$181(46.5)$

Moderate

$100(25.7)$

Severe

$12(3.1)$

Hospitalization

Hospitalized

$174(44.7)$

Not hospitalized

$215(55.3)$

*) Hypertension, type 2 diabetes mellitus, heart disease, chronic pulmonary obstructive disease, asthma, autoimmune disease, hematological disease, and cancer. **) Nurse, midwifes, nutritionist, etc. ${ }^{* * *)}$ Drivers, housemaid, security, etc. 
Long COVID-19 symptoms ( $n=192)$

Anxiety $108(56.5)$

Chronic fatigue 89 (46.6)

Cough $40(20.9)$

Myalgia $31(16.2)$

Decreased of lung functional capacity $28(14.7)$

Decreased of cognitive function and attention $23(12.0)$

Hypogeusia

Hyposmia

Decreased of appetite

$8(4.2)$

*) Hypertension, type 2 diabetes mellitus, heart disease, chronic pulmonary obstructive disease, asthma, autoimmune disease, hematological disease, and cancer. **) Nurse, midwifes, nutritionist, etc. $\left.{ }^{* *}\right)$ Drivers, housemaid, security, etc.

Clinical manifestations, comorbidities, and long haulers of COVID-19. Of all participants, $46.5 \%$ experienced mild disease, $25.7 \%$ had moderate disease, and $3.1 \%$ had severe disease. Fever, myalgia, and cough were reported as the common symptoms of the COVID-19. Comorbidities were reported among $55 \%$ of these participants. The most common comorbidity was lung diseases $(23.4 \%)$, followed by hypertension (18.2\%), type 2 diabetes mellitus (7.9\%), autoimmune disease (5.1\%), heart disease (2.3\%), hematologic disease $(1.4 \%)$, cancer $(0.5 \%)$.

Several symptoms were still reported by 192 (49.9\%) after the PCR SARS-CoV-2 examination were negative. Most of the long COVID-19 symptoms experienced by the participants were anxiety (56.5\%), chronic fatigue (46.6\%), and cough (20.9\%) as seen in Table 1.

Factors associated with moderate-severe of COVID-19 infection. We identified four factors that associated with moderate-severe of COVID-19 infection. Doctors who had moderate occupational risk stratification that had contact with many people who unknown their COVID-19 status had a highest risk (aOR 4.14, 95\% Cl: 1.11-15.47; $p=0.034$ ) while middle age doctors (40-59 years) had 3.2 higher risk to develop severe COVID-19 infection (95\% Cl: 1.99-5.29; $p<0.001$ ) than doctors age 20-39 years old. Other associated factors were working in COVID-19 designated hospital (aOR 1.89, 95\% Cl: 1.18-3.01; p=0.008) and higher BMI (aOR 1.88, 95\% Cl: 1.00-3.54; $\mathrm{p}=0.049)$ (Table 2). 
Table 2

Factors associated with moderate-severe COVID-19 infection among doctors in Indonesia.

\begin{tabular}{|c|c|c|c|c|c|c|}
\hline & $\begin{array}{l}\text { Moderate } \\
\text { - severe }\end{array}$ & $\begin{array}{l}\text { Asymptomatic } \\
\text { - mild }\end{array}$ & Bivariate ar & lysis & $\begin{array}{l}\text { Multivaria } \\
\text { analysis }\end{array}$ & \\
\hline & $\mathrm{n}(\%)$ & $\mathrm{n}(\%)$ & $\begin{array}{l}\mathrm{OR}(95 \% \\
\mathrm{Cl})\end{array}$ & $\begin{array}{l}P \\
\text { value }\end{array}$ & $\begin{array}{l}\text { OR }(95 \% \\
\mathrm{Cl})\end{array}$ & $\begin{array}{l}\mathrm{P} \\
\text { value }\end{array}$ \\
\hline $\begin{array}{l}\text { Age } \\
\geq 60 \text { years } \\
40-59 \text { years } \\
20-39 \text { years }\end{array}$ & $\begin{array}{l}3(25.0) \\
50(47.2) \\
59(21.8)\end{array}$ & $\begin{array}{l}9(75.0) \\
56(52.8) \\
212(78.2)\end{array}$ & $\begin{array}{l}1.19(0.31 \\
-4.56) \\
3.21(1.98 \\
-5.17) \\
1\end{array}$ & $\begin{array}{l}0.792 \\
<0.001\end{array}$ & $\begin{array}{l}1.05 \\
(0.27- \\
4.12) \\
3.24 \\
(1.99- \\
5.29)\end{array}$ & $\begin{array}{l}0.938 \\
<0.001\end{array}$ \\
\hline $\begin{array}{l}\text { Gender } \\
\text { Male } \\
\text { Female }\end{array}$ & $\begin{array}{l}53(31.7) \\
59(26.6)\end{array}$ & $\begin{array}{l}114(68.3) \\
163(73.4)\end{array}$ & $\begin{array}{l}1.28(0.82 \\
-1.99) \\
1\end{array}$ & 0.266 & & \\
\hline $\begin{array}{l}\text { Marrital status } \\
\text { Married } \\
\text { Not married }\end{array}$ & $\begin{array}{l}92(31.6) \\
20(20.4)\end{array}$ & $\begin{array}{l}199(68.4) \\
78(79.6)\end{array}$ & $\begin{array}{l}0.55(0.32 \\
-0.96) \\
1\end{array}$ & 0.034 & $\begin{array}{l}0.75 \\
(0.41- \\
1.35)\end{array}$ & 0.344 \\
\hline $\begin{array}{l}\text { Profession } \\
\text { General practitioner } \\
\text { Resident } \\
\text { Specialist - Consultant }\end{array}$ & $\begin{array}{l}62(31.6) \\
9(12.3) \\
41(34.2)\end{array}$ & $\begin{array}{l}134(68.4) \\
64(87.7) \\
79(65.8)\end{array}$ & $\begin{array}{l}1.10(0.66 \\
-1.78) \\
3.57(1.60 \\
-7.99) \\
1\end{array}$ & $\begin{array}{l}0.728 \\
0.002\end{array}$ & $\begin{array}{l}1.18 \\
(0.65- \\
2.12) \\
0.50 \\
(0.21- \\
1.19)\end{array}$ & $\begin{array}{l}0.580 \\
0.119\end{array}$ \\
\hline $\begin{array}{l}\text { Working in COVID-19 } \\
\text { designated hospital } \\
\text { Yes } \\
\text { No }\end{array}$ & $\begin{array}{l}59(24.3) \\
53(36.3)\end{array}$ & $\begin{array}{l}184(75.7) \\
93(63.7)\end{array}$ & $\begin{array}{l}1.77(1.14 \\
-2.77) \\
1\end{array}$ & 0.011 & $\begin{array}{l}1.89 \\
(1.18- \\
3.01)\end{array}$ & 0.008 \\
\hline $\begin{array}{l}\text { Smoking status } \\
\text { Yes } \\
\text { No }\end{array}$ & $\begin{array}{l}1(14.3) \\
111(29.1)\end{array}$ & $\begin{array}{l}6(85.7) \\
271(70.9)\end{array}$ & $\begin{array}{l}0.40(0.05 \\
-3.41) \\
1\end{array}$ & 0.678 & & \\
\hline $\begin{array}{l}\text { Working hours per } \\
\text { week } \\
>40 \text { hours } \\
\leq 40 \text { hours }\end{array}$ & $\begin{array}{l}39(23.6) \\
73(32.6)\end{array}$ & $\begin{array}{l}126(76.4) \\
151(67.4)\end{array}$ & $\begin{array}{l}0.64(0.40 \\
-1.00) \\
1\end{array}$ & 0.054 & $\begin{array}{l}0.92 \\
(0.55- \\
1.53)\end{array}$ & 0.749 \\
\hline
\end{tabular}




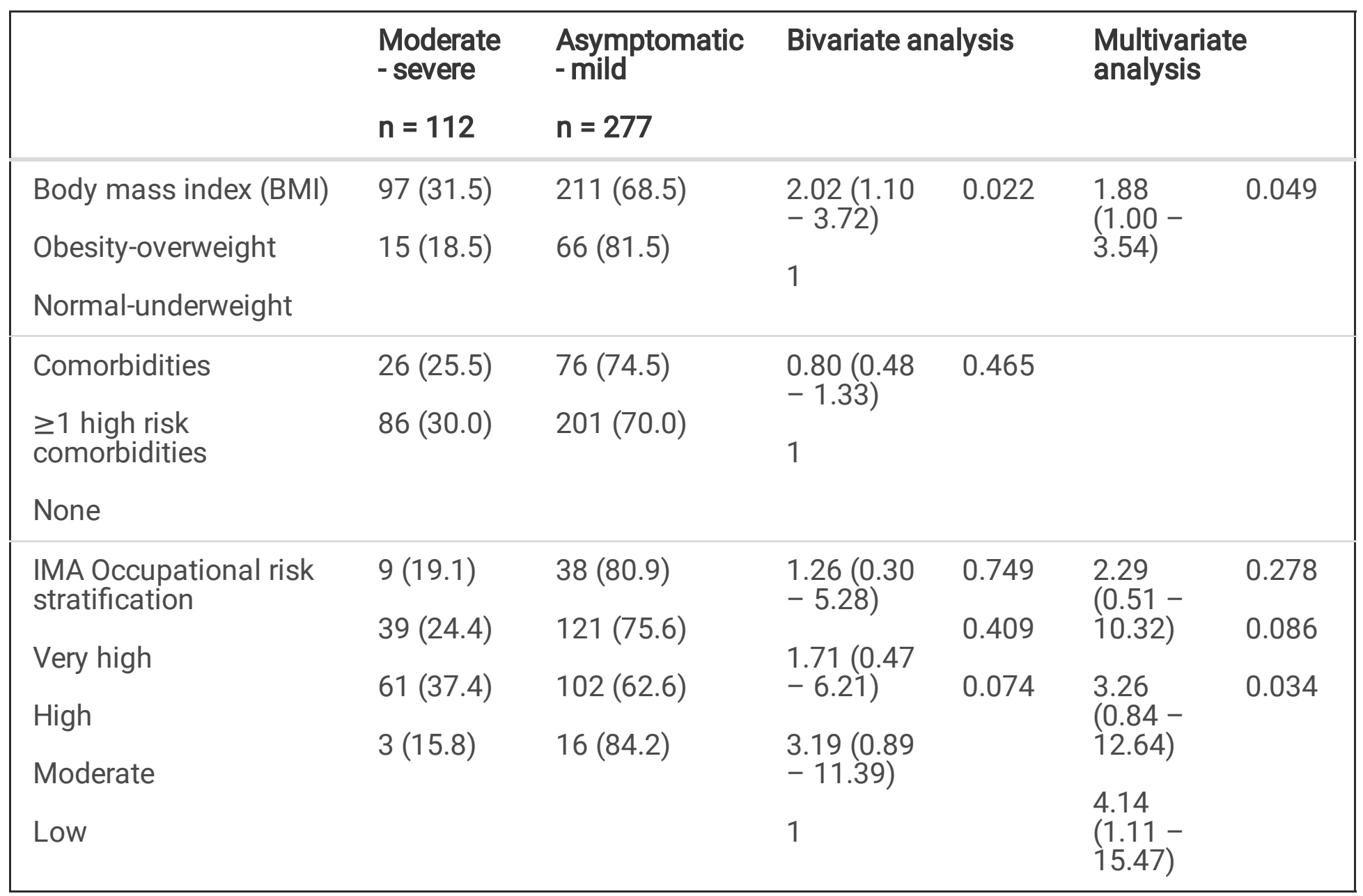

Behavioral adaptation of PPE usage before and after got COVID-19 infection. Before being infected with COVID-19, N95 respirators were used by $85 \%$ doctors working in isolation rooms, $70.2 \%$ confirmed always use $\mathrm{N} 95$ mask and $15.8 \%$ sometimes use N95. Others used KN-95 regularly (3.5\%), KN-95 not-regularly $(0.9 \%)$, only surgical mask regularly $(4.4 \%)$, only surgical mask not regularly (3.5\%), and only using fabric mask (1.8\%). After recovering from COVID-19, the numbers of doctors who always use N95 increase to $80.9 \%$ and doctors who sometimes use N95 was decreased to $13.2 \% .1 .8 \%$ of them still use surgical mask only when working in isolation room. Fabric masks were used by 2 doctors (1.8\%) before contracting COVID-19, but none after that (Figure 2A).

Outside the isolation room, before contracting with COVID-19, N95 respirators were routinely used by rank in operating room $(56.0 \%)$, critical care unit $(46.7 \%)$, emergency department $(45.1 \%)$, medical procedure room (42.3\%), non-isolation ward (38.9\%), and outpatient clinic (34.4\%). Some doctors were using surgical mask only: in outpatient clinic (always $17.2 \%$, sometimes $9.7 \%$ ), in medical procedure room (always $14.1 \%$, sometimes $0.7 \%$ ), in non-isolation ward (always $12.2 \%$, sometimes $6.8 \%$ ), in critical care unit (always $8.2 \%$, sometimes $4.9 \%$ ), in emergency department (always $8.0 \%$, sometimes $7.4 \%$ ), and less in operating room (always 6.0\%). Although, we demonstrated better trends in N95 respirator used after these doctors recovered from COVID-19, there were still some doctors used surgical mask only in all nonisolation room as seen in figure 2B-G. We identified there were some doctors who even used fabric masks 
only when working in non-isolation room: 3 doctors in medical procedure room, 2 doctors in emergency department, 2 doctors in outpatient clinic, and 1 doctor in non-isolation ward. After recovering from COVID-19, one doctor still used fabric mask only when working in emergency department.

Overall practices of using other PPE were improved after doctors survived from COVID-19 infection as seen in figure 3. Of the 114 doctors working in isolation rooms, $83.3 \%$ doctors routinely used headcap, $83.3 \%$ routinely used face protectors, $62.3 \%$ routinely used eye protectors, $81.6 \%$ routinely used hazmat suit, routinely used gown $53.5 \%, 71.1 \%$ boots, and $86.8 \%$ routinely used gloves before getting COVID-19 infection. The trends were increasing in all types of PPEs after they survived from COVID-19 infection as seen in figure $3 \mathrm{~A}$.

In non-isolation room, the routinely use of headcap, face protectors, gown, and gloves were also increased once these doctors doing medical practice after recovering from COVID-19 as seen in Figure 3B-G. Better patterns were seen in operating room even before getting COVID-19 infection, except the use of face protector, eye protector, and boots (Figure 3G).

\section{Discussion}

In this nationwide cross-sectional survey, there were more asymptomatic or mild cases than moderate or severe cases. Our participants were doctors, so they tend to have a higher awareness of health problems and initial symptoms of COVID-19. However, we are aware that some doctors who experienced severe or critical COVID-19 infection are not survived and accounted for in this survey. At the end of this survey period, 374 doctors in Indonesia died of COVID-19, as reported by IMA. ${ }^{11}$

This study showed that the most suspected transmission source was from the patient (47.9\%), and the most suspected transmission location was in health care facilities or their workplaces (80.5\%). This result was similar to Zabarsky, et al., who reported that exposure at the workplace to the infected patient was the most transmission source in HCWs with COVID-19 infection in Cleveland, USA, especially in the early pandemic. Exposures to infected patients occurred when recognition of COVID-19 was delayed due to atypical clinical manifestation ${ }^{19,20}$. Difficulties in distinguishing patients with COVID-19 and non-COVID19 due to limited diagnostic tests might impact the prolonged exposure of SARS-CoV-2 in health care workers ${ }^{8}$. Therefore, some of the COVID-19 patients might be seen in non-isolation rooms, especially in emergency department and non-isolation wards. Until late 2020, SARS-CoV-2 antibody was used routinely as screening to differentiate the COVID-19 and non-COVID-19 cases before the availability of PCR SARSCoV-2. Serological tests might be cheaper and easier to implement at the point of care during pandemic. Because of the higher risk of bias and lower accuracy of serological test, the doctors should be careful when interpreting the result ${ }^{21}$.

Exposure to other doctors was thought to be responsible for $15.4 \%$ of the infection, while $7.5 \%$ was from other HCWs such as nurses, midwives, and nutritionists. These transmissions probably occurred when 
these doctors or other HCWs were asymptomatic and still worked despite having symptoms of COVID-19 infection. This condition also associated with occupational risk stratification and severe COVID-1919. Doctors who had close contact with patients who were unknown their COVID-19 status (IMA moderate occupational risk) had a greater risk of severe COVID-19. Early study in Wuhan Hospital in China identified $34.9 \%$ HCWs who infected COVID-19 were asymptomatic ${ }^{22}$.

Gibson, et al., showed that older age was correlated with severe COVID-19 illness in HCWs who worked directly with the patients. Doctor age $\geq 65$ years old had 9.2 fold higher $(95 \% \mathrm{Cl}: 6.3-13.3$ ) to get severe COVID-19 infection ${ }^{23}$. Older age has a role in the efficiency of the binding of S Protein SARS-CoV-2 with ACE-2 24,25 . Compared to doctors age 20-39 years, the proportion of moderate-severe COVID-19 cases was higher in doctors age 40-59 years, but not in doctors age above 60 years. In Indonesia, older doctors age $\geq 60$ years were encouraged not to practice or work directly with the patients during the pandemic. We only had 12 doctors age above 60 years old responded to the study invitation. This group was under representative in this survey, probably because the high mortality due to COVID-19 infection. A large epidemiological study in Jakarta showed that the highest mortality rate was among patient above 70 years $(34 \%)$, followed by $60-69$ years $(22 \%)^{26}$.

In our study, we found that there was not association of comorbidities and moderate-severe COVID-19 infection. Our study is contrast with the latest meta-analysis by Li, et al., showed that there were association of comorbidities such as hypertension, diabetes, chronic renal disease, chronic lung disease, chronic heart disease, and malignancy and severe COVID-19 infection ${ }^{12}$. Gibson, et al., also reported that doctors who had one or more high-risk comorbidities had 29.6 fold higher ( $95 \% \mathrm{Cl}$ : 23.5-36.4) to get severe COVID-19 illness ${ }^{23}$.

The proportion of doctors experiencing severe COVID-19 were higher in those who worked in designated COVID-19 hospital. Indonesian government has appointed as much as 903 hospitals, including private hospital as COVID-19 designated hospitals in late 202027. Working in COVID-19 designated hospital might expose them with more COVID-19 patients and longer duration of exposure. Although not all working in isolation room, there was a possibility that they were still contacted with asymptomatic of undiagnosed COVID-19 patients.

The other factor associated with moderate-severe COVID-19 infection is higher BMI (overweight and obesity). Obesity may contribute to the increased morbidity in COVID-19 infection due to dysregulated immune response that increased production of inflammatory cells and induced airway hyperresponsiveness ${ }^{28,29}$. Our study showed a higher risk of moderate-severe COVID-19 in those with obesity and overweight (aOR 1.88: 1.00-3.54; $p=0.049$ ). Finding in our study is concordance with the latest metaanalysis by Huang, et al., that showed obesity increases the risk for severe COVID-19 infection (aOR 2.09: 1.67-2.62; $\mathrm{p}<0.001)$. Severe COVID-19 was defined by four clinical outcomes: hospitalization, ICU admission, invasive mechanical ventilator (IMV) support, and death, while in our study we could not incorporate death as the outcome of COVID-19 infection ${ }^{30}$. 
A significant number of participants (49.2\%) still had complaints after recovered from COVID-19 or stated that the examination results were negative. A recent meta-analysis estimated that $80 \%$ (95\% Cl: $65-92 \%)$ of the infected patients with SARS-CoV-2 developed one or more long-term symptoms ${ }^{31}$. The anxiety symptom (56.5\%) was the most sequelae experienced by doctors who survived COVID-19, followed by chronic fatigue (46.6\%), cough (20.9\%), myalgia (16.2\%), and decreased lung capacity in performing daily activities (14.7\%). Rogers, et al., showed that adults have a double risk of being newly diagnosed with psychiatric disorder after the COVID-19 diagnosis, and the most common psychiatric conditions was anxiety disorder ${ }^{32}$. Fatigue was the main symptom of patients with long COVID-19 in two metaanalyses ${ }^{31,33}$. In those two meta-analyses, the pooled prevalence of fatigue as long COVID-19 symptom were $63.9 \%$ (95\% Cl: $54-73 \%$ ) and 58\% (95\% Cl: 42-73\%), respectively ${ }^{31,33}$. This symptom will extend on several occasions beyond seven months after the onset of illness and causing significant disability 34 . Moreover, meta-regression analysis showed that fatigue was associated with poor quality of life $\mathrm{e}^{33}$. Though our study showed a lower proportion of long COVID-19 symptoms, because doctors played an essential role in managing during the pandemic, good rehabilitation and clinical management strategies to overcome these long COVID-19 symptoms are warranted.

Although fabric mask should not be worn by HCWs as the level of security is not acceptable in medical facilities, some of doctors used this type of mask before getting COVID-19, even in isolation room. Several studies shown that fabric masks have only marginal protection in preventing droplet infection compared to $\mathrm{N} 95$ mask $^{35,36}$. The difficulties to access the appropriate mask due to shortage was probably the strongest reason for this unsafe practice. Not all health care facilities provided appropriate type and number of masks for their staffs, especially in the early pandemic ${ }^{17}$. Therefore, most of the doctors need to provide their own masks and other PPEs as needed.

\section{Limitation}

This study should be seen in light with some limitations. The study was an online-based survey, thereby underreporting was very likely. The invitation was using social media platforms. It depends on the willingness of participants and might be restricted to only those with good internet access. As a consequent, our study was unlikely to represent of the whole Indonesian doctors survived from COVID-19 infection, especially from east Indonesia. Participants might also give wrong information in this data collection method that can not be confirmed. Recall bias may affect the accuracy of self-reported symptoms and disease classification, not to mention the PPE practice before being infected with COVID19. However, to the best of our knowledge, this is the first report of COVID-19 infected doctors during the pandemic in Indonesia. Another limitation was occured as a result of a cross-sectional study design. Therefore, the definitive cause and effect associations can not be determined.

\section{Conclusion}


In this cross-sectional survey, several factors were associated with moderate-severe COVID-19 infection among doctors in Indonesia, including IMA moderate occupational risk, middle-aged doctors, worked in COVID-19 designated hospitals, and higher BMI. Adequately PPEs were a crucial factor that could be preventing doctors from getting COVID-19 infection. Although, getting adequate PPEs was still challenging, these doctors showed improvement in PPEs used after recovered from COVID-19 infection both in isolation and non-isolation rooms.

\section{Declarations}

\section{Data availability}

The data could be obtained by request to author's email (evy.yunihastuti@gmail.com.)

\section{Authors contributions}

Design and conceptualized study (E.Y., and A.F.S.); project management and coordination for research activity planning and execution (E.Y., A.F.S., and A.W.); data curation, methodology, formal analyses study data, interpreting data, writing and editing the manuscript for intellectual content (E.Y., A.F.S., H.H., D.S.S., and A.W.); visualization manuscript (E.Y., and A.W.); and funding acquisition for this project leading to this publication (E.Y., and A.F.S.).

\section{Competing interest}

The authors declare no competing interests for this study.

\section{References}

1. Ruan, S. Likelihood of survival of coronavirus disease 2019. Lancet Infect. Dis, 20, 630-631 (2020).

2. World Health Organization. 2019-nCoV outbreak is an emergency of international concern. (2020). Available at: https://www.euro.who.int/en/health-topics/health-emergencies/international-healthregulations/news/news/2020/2/2019-ncov-outbreak-is-an-emergency-of-international-concern. (Accessed: 1st September 2021)

3. Satuan Tugas Penanganan COVID-19 \& Peta Sebaran, C. O. V. I. D. 2021 Available at: https://covid19.go.id/peta-sebaran-covid19. (Accessed: 17th June 2021)

4. Roy, D. et al. Study of knowledge, attitude, anxiety \& perceived mental healthcare need in Indian population during COVID-19 pandemic. Asian J. Psychiatr, 51, 1-7 (2020).

5. European Centre for Disease Prevention and Control. Infection prevention and control and preparedness for COVID-19 in healthcare settings. (2021).

6. Wong, L. Y., Tan, A. L., Leo, Y. S., Lee, V. J. M. \& Toh, M. P. H. S. Healthcare workers in Singapore infected with COVID-19: 23 January-17 April 2020. Influ. Other Respi Viruses, 15, 218-226 (2021). 
7. Kambhampati, A. K. et al. COVID-19 - Associated Hospitalizations Among Health Care Personnel COVID-NET, 13 States, March 1-May 31, 2020. Morb. Mortal. Wkly. Rep, 69, 1576-1583 (2020).

8. Ali, S., Farooq, I., Bugshan, A. \& Vohra, F. Risk Assessment of healthcare workers at the frontline against COVID-19. Pakistan J. Med. Sci, 36, S1-S5 (2020).

9. Wang, J., Zhou, M. \& Liu, F. Reasons for healthcare workers becoming infected with novel coronavirus disease 2019 (COVID-19) in China. J. Hosp. Infect, 105, 100-101 (2020).

10. Xiang, Y. T. et al. Tribute to health workers in China: A group of respectable population during the outbreak of the COVID-19. Int. J. Biol. Sci, 16, 1739-1740 (2020).

11. Ikatan Dokter Indonesia. Pandemi COVID-19 update: data kematian dokter Indonesia. (2021).

12. Li, J. et al. Epidemiology of COVID-19: a systematic review and meta-analysis of clinical characteristics, risk factors, and outcomes. J. Med. Virol, 93, 1449-1458 (2021).

13. Zhou, Y., Chi, J., Lv, W. \& Wang, Y. Obesity and diabetes as high-risk factors for severe coronavirus disease 2019 (Covid-19). Diabetes. Metab. Res. Rev, 37, e3377 (2021).

14. Gao, Y. et al. Risk factors for severe and critically ill COVID-19 patients: a review. Allergy, 76, 428-455 (2021).

15. Cattaruzza, M. S. et al. Covid-19 and the role of smoking: the protocol of the multicentric prospective study COSMO-IT (COvid19 and SMOking in ITaly). Acta Biomed, 91, e2020062 (2020).

16. World Health Organization. Rational use of personal protective equipment for COVID-19 and considerations during severe shortages. (2020).

17. Jain, U. Risk of COVID-19 due to shortage of personal protective equipment. Cureus, 12, e8837 (2020).

18. Ikatan Dokter Indonesia. Pedoman standar perlindungan dokter di era COVID-19 (PB Ikatan Dokter Indonesia (PB IDI), 2020).

19. Zabarsky, T. F. et al. What are the sources of exposure in healthcare personnel with coronavirus disease 2019 infection? Am. J. Infect. Control, 49, 393-395 (2021).

20. Kang, M. \& Perl, T. M. The front-line during the coronavirus disease 2019 pandemic: healthcare personnel. Curr. Opin. Infect. Dis, 34, 372-383 (2021).

21. Bastos, M. L. et al. Diagnostic accuracy of serological tests for covid-19: systematic review and meta-analysis. $B M J, \mathbf{3 7 0}, 1-13$ (2020).

22. Zhang, S. et al. Factors associated with asymptomatic infection in health-care workers with severe acute respiratory syndrome coronavirus 2 infection in Wuhan, China: a multicentre retrospective cohort study. Clin. Microbiol. Infect, 26, 1670-1675 (2020).

23. Gibson, D. M. \& Greene, J. Risk for severe COVID-19 illness among health care workers who work directly with patients. J. Gen. Intern. Med, 35, 2804-2806 (2020).

24. Swärd, P. et al. Age and sex differences in soluble ACE2 may give insights for COVID-19. Crit. Care, 24, $221(2020)$. 
25. Attaway, A. H., Scheraga, R. G., Bhimraj, A., Biehl, M. \& Hatipoğlu, U. Severe covid-19 pneumonia: pathogenesis and clinical management. BMJ, 372, n436 (2021).

26. Surendra, H. et al. Clinical characteristics and mortality associated with COVID-19 in Jakarta, Indonesia: a hospital-based retrospective cohort study. Lancet Reg. Heal. - West. Pacific, 9, 100108 (2021).

27. Kementerian Kesehatan Republik Indonesia. Ruang isolasi COVID-19 di semua provinsi masih memadai. Kementerian Kesehatan Republik Indonesia (2020). Available at: https://www.kemkes.go.id/article/print/20101300001/ruang-isolasi-covid-19-di-semua-provinsimasih-memadai.html. (Accessed: 1st September 2021)

28. Dixon, A. E. \& Peters, U. The effect of obesity on lung function. Expert Rev. Respir. Med, 12, 755-767 (2018).

29. Soeroto, A. Y. et al. Effect of increased BMI and obesity on the outcome of COVID-19 adult patients: a systematic review and meta-analysis. Diabetes Metab. Syndr. Clin. Res. Rev, 14, 1897-1904 (2020).

30. Liu, C. H. et al. A noninvasive diagnosis of hepatic fibrosis by BioFibroScore ${ }^{\circledR}$ in chronic hepatitis C patients. J. Gastroenterol. Hepatol, 33, 291-297 (2018).

31. Lopez-Leon, S. et al. More than 50 long-term effects of COVID-19: a systematic review and metaanalysis. Sci. Rep, 11, 16144 (2021).

32. Rogers, J. P. et al. Psychiatric and neuropsychiatric presentations associated with severe coronavirus infections: a systematic review and meta-analysis with comparison to the COVID-19 pandemic. Lancet Psychiatry, 7, 611-627 (2020).

33. Malik, P. et al. Post-acute COVID-19 syndrome (PCS) and health - related quality of life (HRQoL) - A systematic review and meta-analysis.J. Med. Virol.1-10(2021).

34. Maltezou, H. C., Pavli, A. \& Tsakris, A. Post-COVID syndrome: an insight on its pathogenesis. Vaccines, 9, 497 (2021).

35. De Silva, A. P., Niriella, M. A. \& de Silva, H. J. Masks in COVID-19: let's unmask the evidence. Expert Rev. Respir. Med, 15, 293-299 (2021).

36. Rengasamy, S., Eimer, B. \& Shaffer, R. E. Simple respiratory protection - evaluation of the filtration performance of cloth masks and common fabric materials against $20-1000 \mathrm{~nm}$ size particles. Ann. Occup. Hyg, 54, 789-798 (2010).

\section{Figures}




\section{Participants per province in Indonesia}
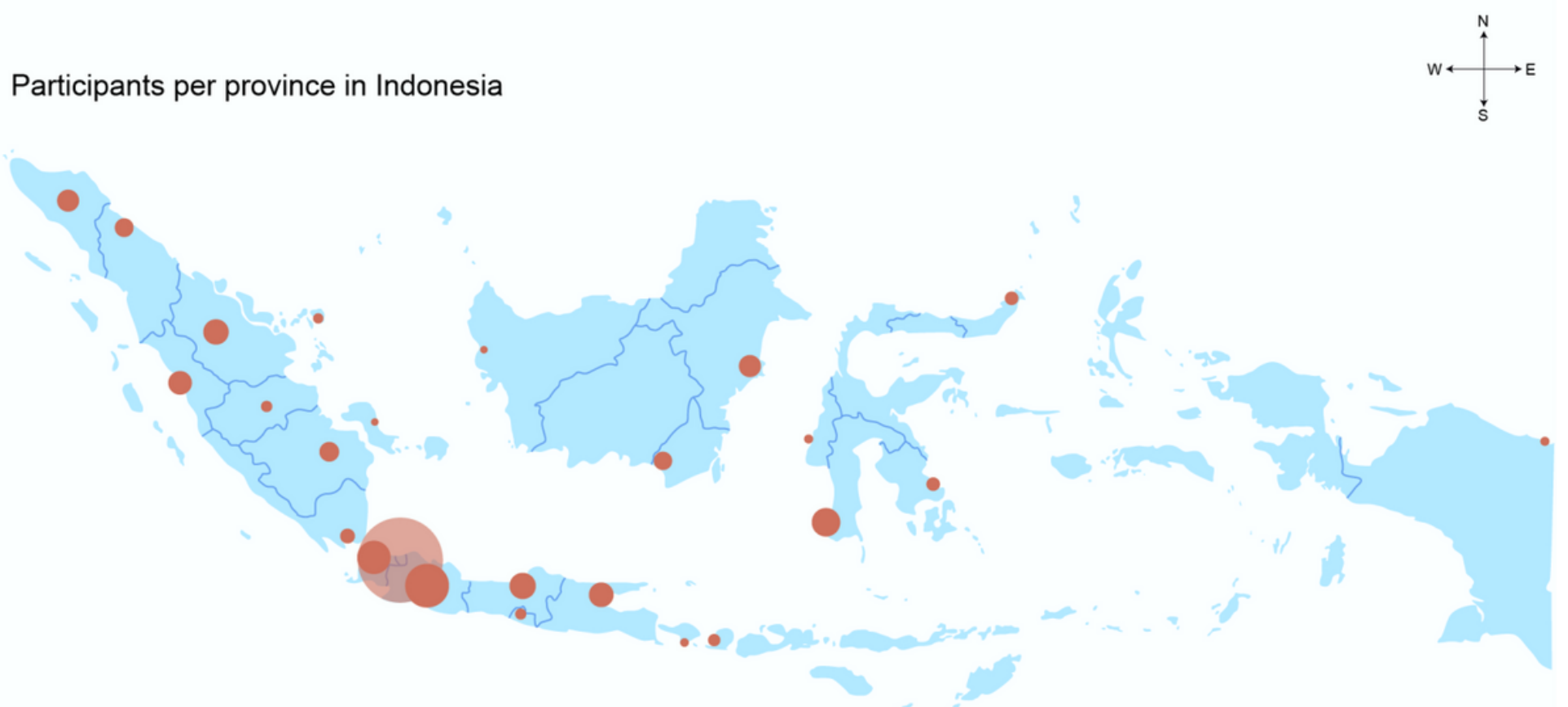

\section{Figure 1}

Participants per province in Indonesia. Size of dots represent number of study participants in each province 
A

ISOLATION WARDS ( $n=114)$

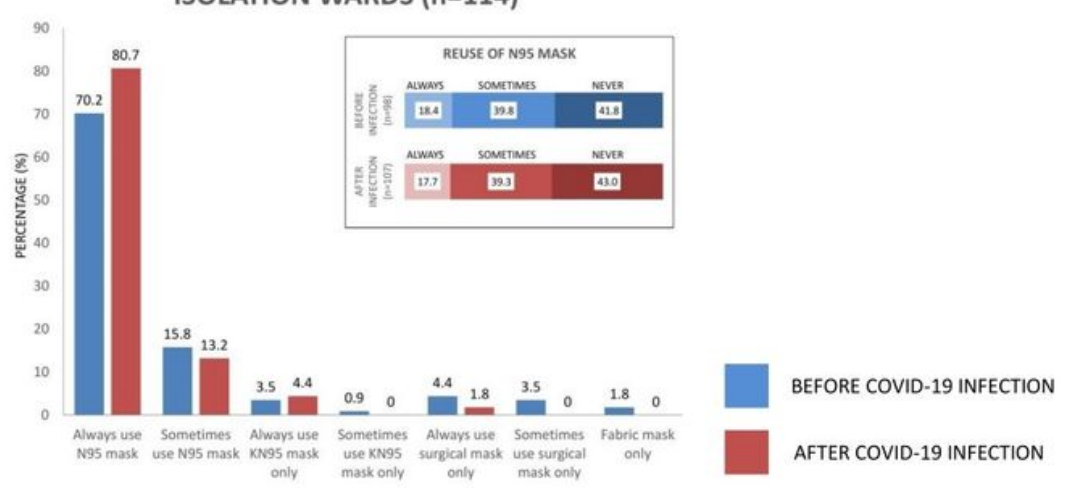

B

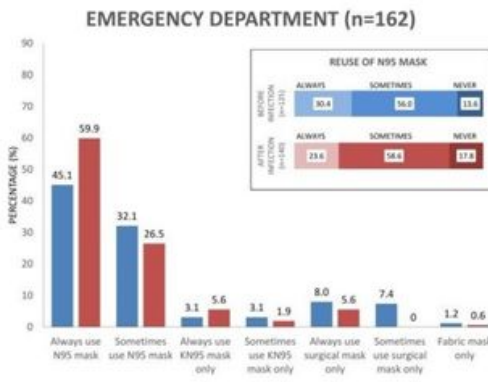

E

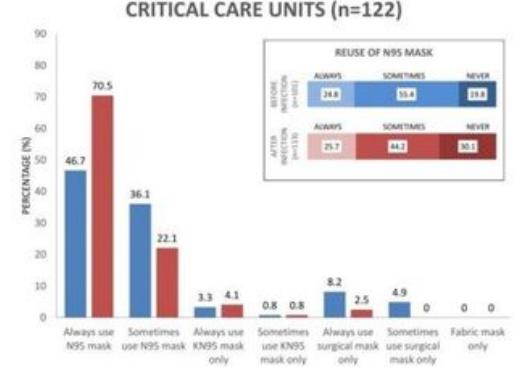

C

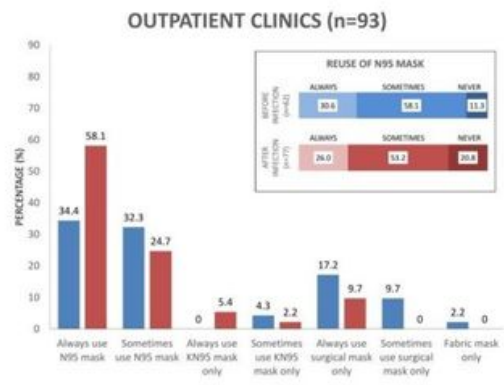

$\mathrm{F}$

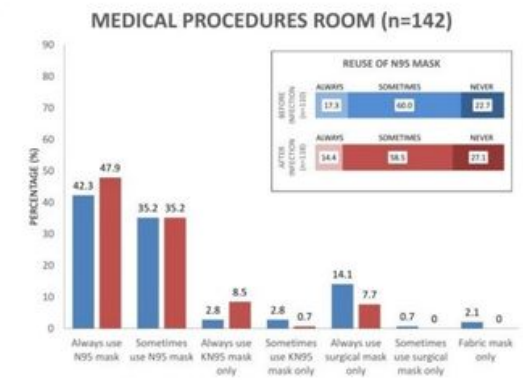

D

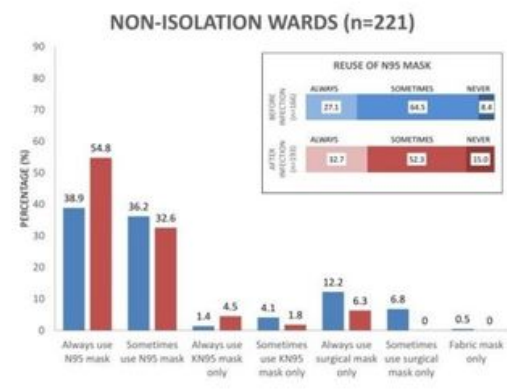

G

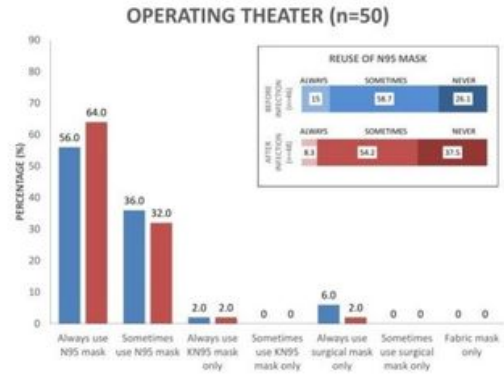

\section{Figure 2}

$\mathrm{N}-95$ mask use in isolation (A) and non-isolation rooms (B-G) before and after COVID-19 infection. 
A ISOLATION WARDS ( $n=114)$

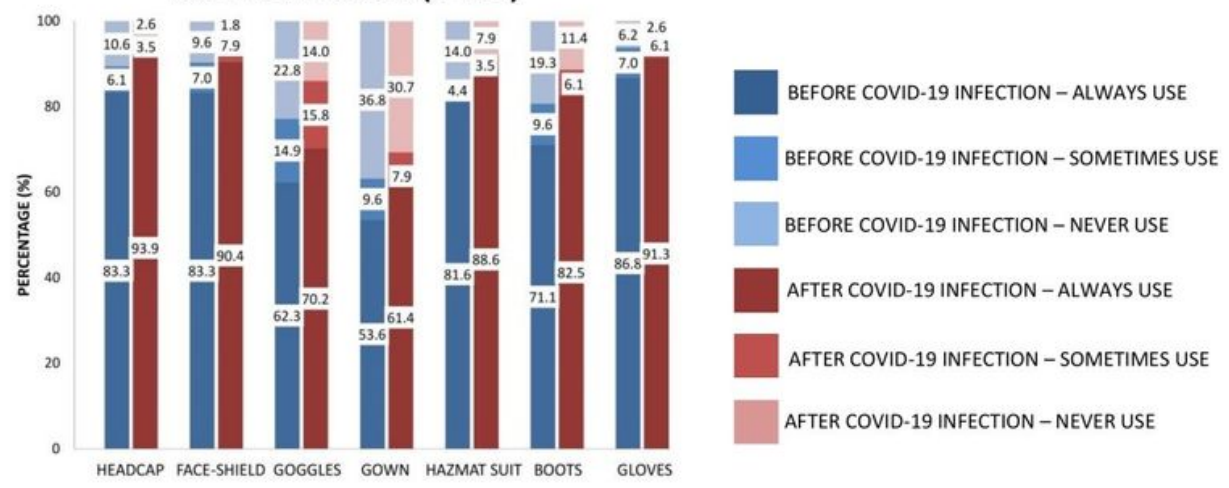

B

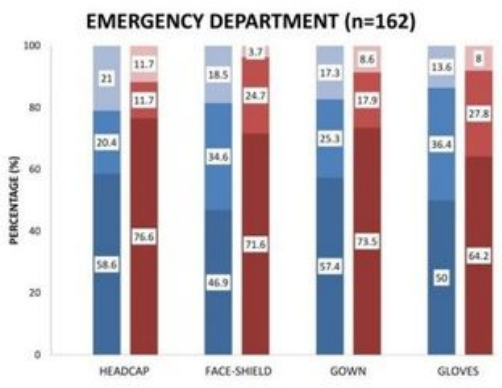

E

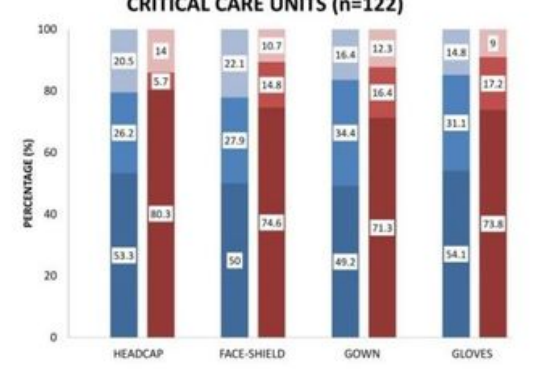

C

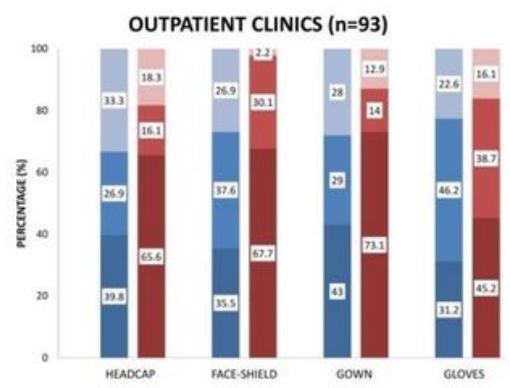

$\mathrm{F}$

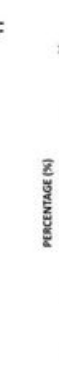

D

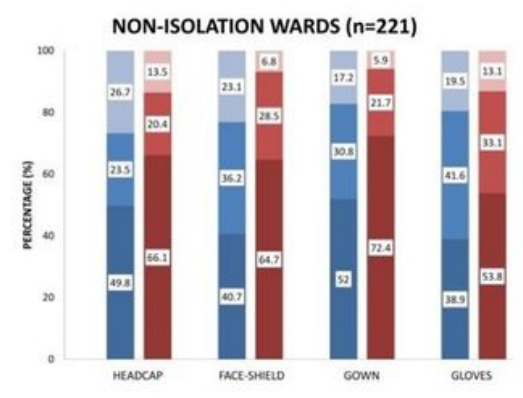

G

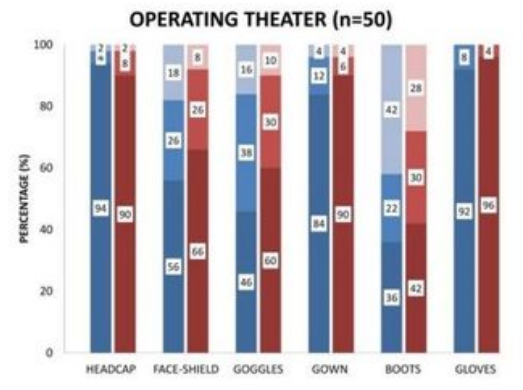

Figure 3

Other PPEs use in isolation (A) and non-isolation rooms (B-G) before and after COVID-19 infection. 